\title{
Experimental investigation by laser flash photolysis to reveal the optical and electron donating properties of benzothiazole derivatives and a theoretical approach by using time-dependent density functional theory (TD-DFT)
}

S. K. Pal, T. Sahu (nee Bhattacharya), T. Misra, P. K. Mallick, M. N.

Paddon-Row_and T. Ganguly_

B3LYP/6-31G(d) optimized geometry of 2-amino-benzothiazole in the gas phase

$\begin{array}{lcccc}0 & 1 & & & \\ \text { H1 } & 0 & -0.8806551 & -2.4711482 & -0.0109494 \\ \text { C2 } & 0 & -1.0410778 & -1.3975519 & -0.0086665 \\ \text { C3 } & 0 & -1.4269054 & 1.4074989 & -0.0019744 \\ \text { C4 } & 0 & 0.0667738 & -0.541562 & -0.0326107 \\ \text { C5 } & 0 & -2.3221544 & -0.8525457 & 0.0175319 \\ \text { C6 } & 0 & -2.5166404 & 0.5359182 & 0.0211856 \\ \text { C7 } & 0 & -0.1472664 & 0.8586105 & -0.0306516 \\ \text { N8 } & 0 & 1.3927902 & -0.9521936 & -0.0464919 \\ \text { H9 } & 0 & -3.1840877 & -1.5137956 & 0.0353303 \\ \text { S10 } & 0 & 1.412677 & 1.6826067 & -0.0722486 \\ \text { H11 } & 0 & -1.5769516 & 2.4830577 & 0.0000194 \\ \text { C12 } & 0 & 2.1882411 & 0.0684613 & -0.0666897 \\ \text { N13 } & 0 & 3.5553727 & -0.022071 & -0.15487 \\ \text { H14 } & 0 & 4.0958562 & 0.7237621 & 0.2630236 \\ \text { H15 } & 0 & 3.9082801 & -0.9503426 & 0.0465968 \\ \text { H16 } & 0 & -3.5242523 & 0.941295 & 0.0414654\end{array}$

